\title{
Pneumococcal immunization program: Cost-utility analysis for Quebec
}

Philippe De Wals MD ${ }^{1,2,3}$, Maryse Guay MD ${ }^{2,3}$, Jean Drapeau MSc ${ }^{4}$, Carole St-Hilaire BSc ${ }^{1}$, Réjean Hébert $M D^{1}$, Jacques Pépin $M^{5}{ }^{5}$, John Spika $M D^{6}$, Richard Béland $\mathrm{PhD}^{2}$

\begin{abstract}
A cost-utility analysis of a pneumococcal immunization program was conducted for Quebec. The goal of this study was to estimate the cost, effectiveness and benefit of an immunization program against pneumococcal infection in Quebec. Two strategies were evaluated using the current situation of infrequent use of 23 -valent polysaccharide vaccine as a reference point. The first strategy - the 'private' program - was a vaccine promotion program, with no change in the current distribution system. The second strategy - the 'public' program - consisted of a promotional program combined with free vaccine distribution through the public health care system. The pneumococcal immunization program targeted practically the same clientele as the influenza program, so that in the two scenarios promotional activities and vaccination were linked.

A cost-utility analysis was conducted for four target groups: persons living in residential and extended care centres, persons with certain predisposing chronic conditions (primarily diabetes and heart or lung disease), persons with human immunodeficiency virus (HIV), and person aged 65 years and over who do not fall into any of the other categories. An additional analysis was conducted for all persons aged 65 years and over, with or without a predisposing chronic condition. Assuming that the same number of individuals would be immunized against influenza and pneumococcus, there would
\end{abstract}

be about 100,000 persons to vaccinate each year when the program was in its maintenance phase, and about 375,000 persons targeted for catch-up.

In the basic scenario, the vaccine was considered of maximum efficacy in preventing invasive infections with bacteremia but less than half as effective in preventing infections without bacteremia, which are twice as common. Sensitivity analyses were conducted on the assumption that the vaccine was totally ineffective in preventing infections without bacteremia or that it was just as effective for both types of infections. The vaccine efficacy rates were taken from the case control study with the most subjects, and reflected reduced efficacy over the course of time and the fact that $10 \%$ of strains are not covered by 23 -valent vaccine. For persons with HIV, we used efficacy estimates from a group of American experts.

In the basic scenario, the total cost of a private program is about $\$ 1$ million, two-thirds of which is borne by individuals through vaccine purchases and one-third by the public sector (vaccination). The unit cost is $\$ 22.80$ per dose. If it was decided to revaccinate individuals at risk after six years, the cost would increase by about $\$ 1.7$ million to a total of $\$ 2.7$ million per year for the program.

In a public program, all costs, a little less than $\$ 800,000$, are borne by the public sector. The unit cost is $\$ 22.10$ per dose. The difference of approximately one-quarter of a million dol-

\footnotetext{
${ }^{I}$ Centre de Recherche de l'Institut universitaire de Gériatrie de Sherbrooke; ${ }^{2}$ Département des Sciences de la Santé Communautaire, Université de Sherbrooke, Sherbrooke, Québec; ${ }^{3}$ Direction de la Santé publique de la Régie régionale de la Santé et des Services sociaux de la Montérégie, Saint-Hubert, Quebec; ${ }^{4}$ Centre de recherche clinique du Centre universitaire de Santé de l'Estrie, Sherbrooke, Québec; ${ }^{5}$ Département de Médecine interne, Université de Sherbrooke, Sherbrooke, Québec; ${ }^{6}$ Laboratory Centre for Disease Control, Health Canada, Ottawa, Ontario

Correspondence and reprints: Dr Phillipe De Wals, Centre U Sante de L'Estrie-Fleur, 3001 12e Avenue Nord, Sherbrook, Quebec J1H 5N4. Telephone 819-564-5348, fax 819-564-5397, pdewals@courrier.usherb.ca
} 
lars is due mainly to the reduced price of vaccines purchased in large quantities ( $\$ 8.25$ per dose). The costs would rise by $\$ 1.2$ million if revaccination after six years were included to a total of $\$ 2$ million per year.

The results of the cost-utility analysis show that, in almost all scenarios, a public program generates financial benefits in two categories of individuals: the chronically ill and persons with HIV. For the chronically ill, costs are slightly higher than the financial benefits only in a scenario of very poor vaccine efficacy. For persons aged 65 and over and in good health, the risk of pneumococcal infection is very low, and the financial benefit of immunization associated with avoided hospitalization is always lower than the costs of vaccination. However, the cost per quality year of life (approximately $\$ 8,000$ without discounting and $\$ 13,000$ with a discount rate of $5 \%$ ) compares favourably with other health measures. For persons in residential and extended care centres, the cost effectiveness and cost-utility ratios are much less advantageous because of the poor life expectancy and quality of life of these individuals; however, they do not form a large group, and the associated costs are low.

In a public program for all persons over 65 years of age, with or without chronic conditions, the costs are significantly higher than the financial benefits, whether the benefits are discounted or not. Without discounting, the net cost per year of quality life is $\$ 1,700$, and the discounted value is $\$ 3,000$. Systematic revaccination after six years increases the cost effectiveness and cost-utility ratios by $20 \%$.

For all groups at risk, the net cost of a public program in its maintenance phase, with vaccination coverage rates equivalent to those for influenza and the benefits associated with avoided hospitalizations taken into account, is approximately $\$ 200,000$ per year (or $\$ 5.80$ per dose). With expenses and financial benefits discounted at the rate of $5 \%$, the net cost of the program is on the order of $\$ 300,000$ per year (or $\$ 8.50$ per dose).

In conclusion, pneumococcal immunization is a health measure that compares favourably with other programs and services provided to senior citizens or persons with chronic conditions. The costs and benefits of immunization vary widely from one category of recipient to another, but, from a societal standpoint, a public program is always preferable to a private one because of the savings achieved from the purchase of large quantities of vaccine.

ACKNOWLEDGEMENTS: This study was conducted with a grant from the Conseil d'évaluation des technologies en santé du Québec. 


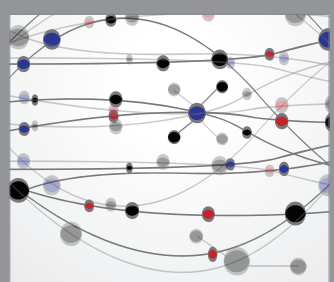

The Scientific World Journal
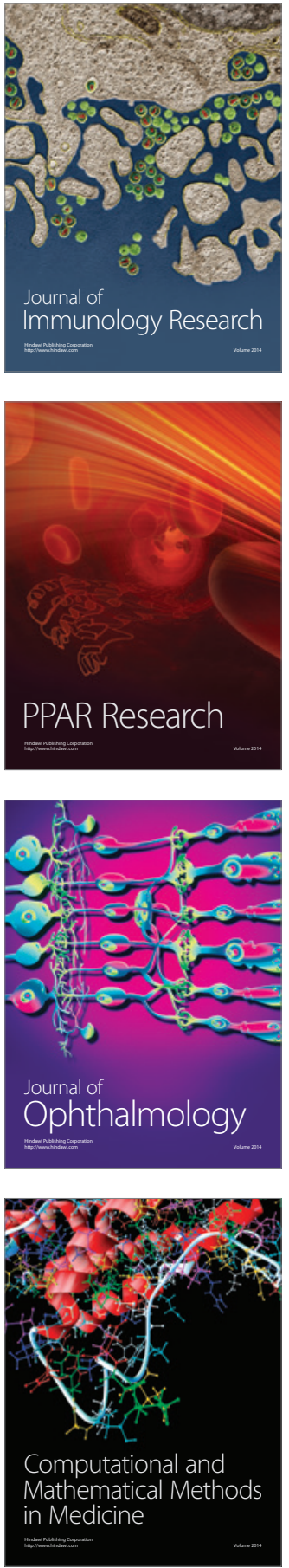

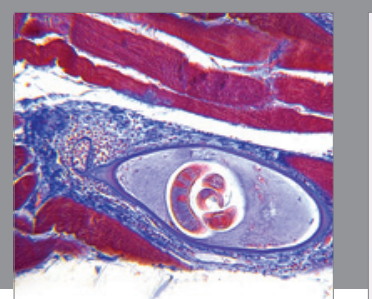

Gastroenterology Research and Practice

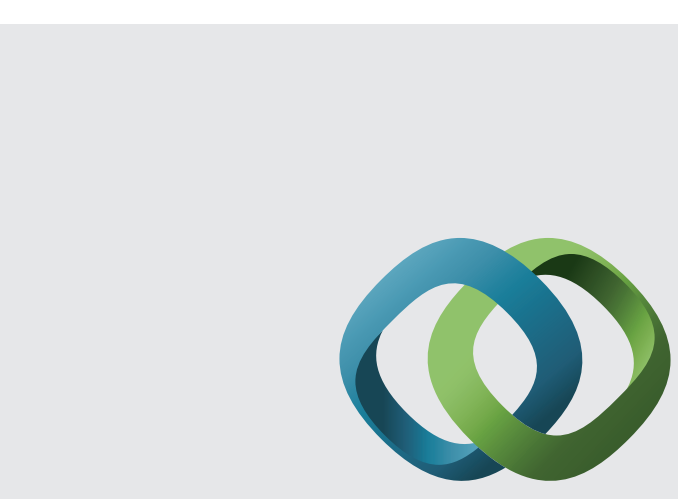

\section{Hindawi}

Submit your manuscripts at

http://www.hindawi.com
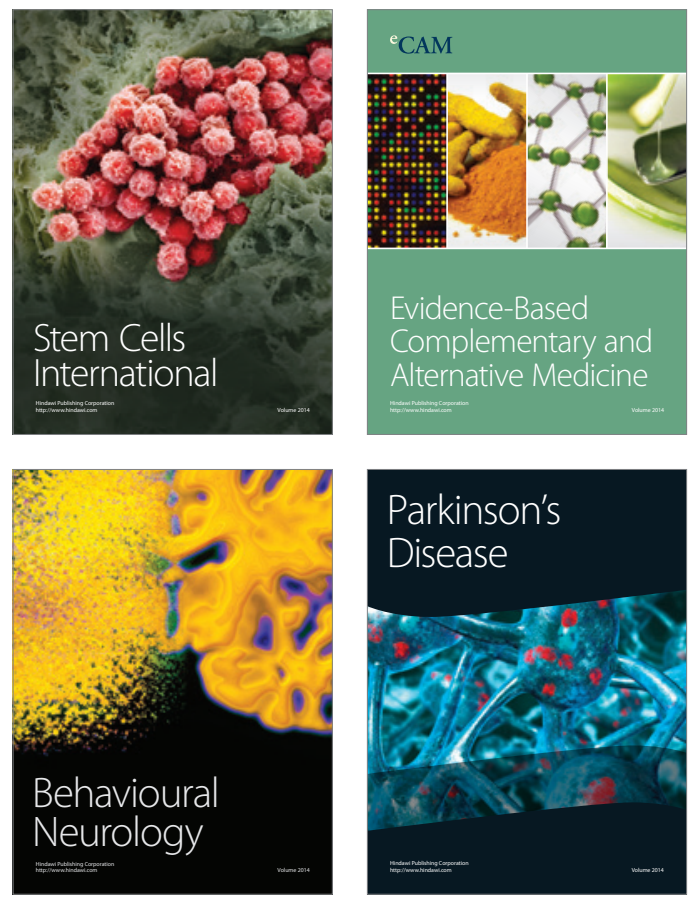
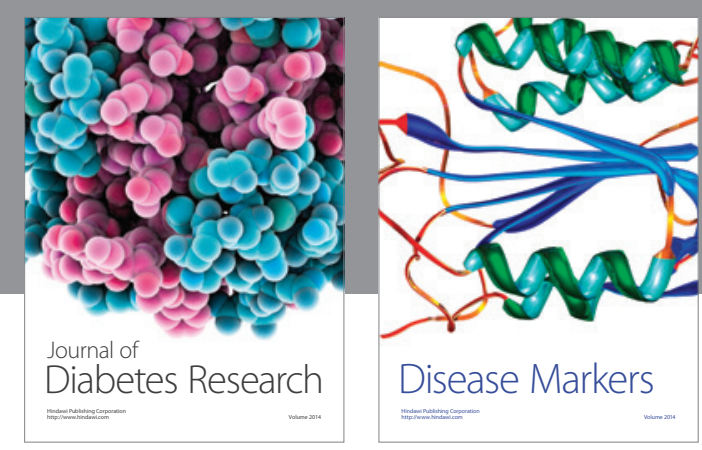

Disease Markers
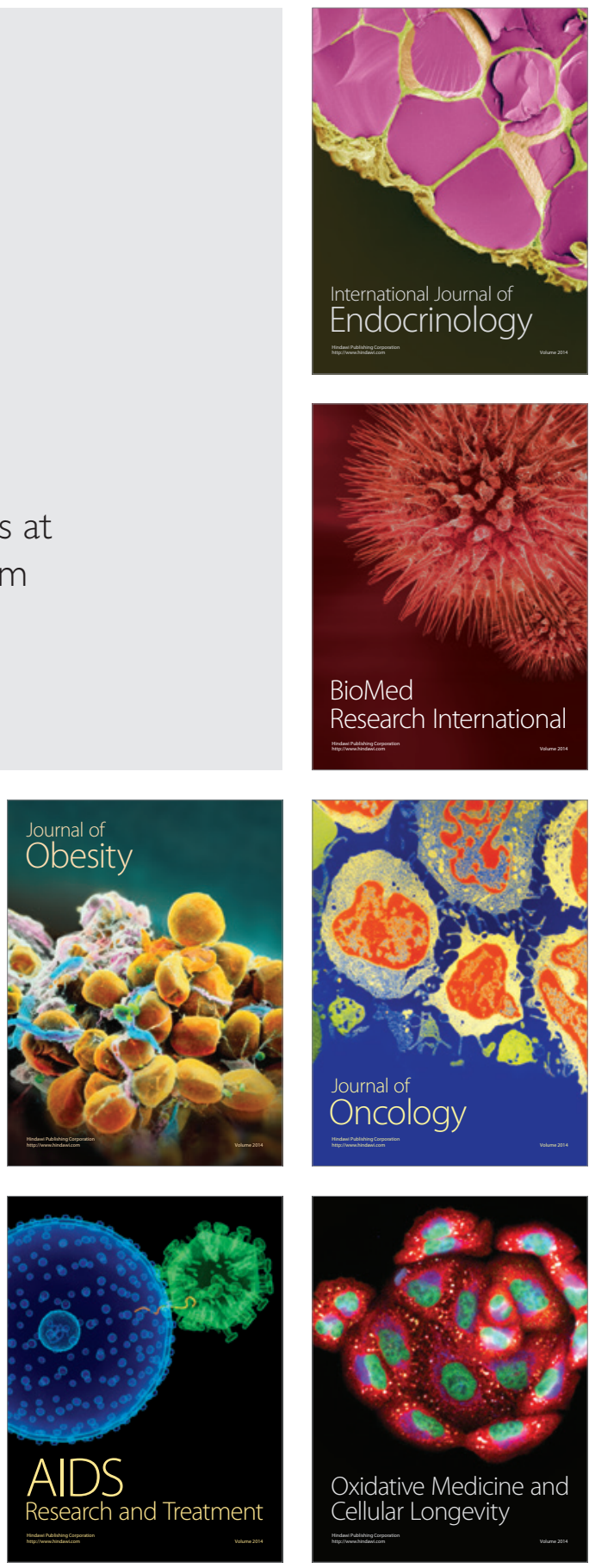